\author{
Mediterranean BioMedical Journals \\ Integrative Journal of Medical Sciences \\ 2020, Volume 7, ID 205 \\ DOI: 10.15342/ijms.7.205
}

RESEARCH ARTICLE

\title{
Impact of Covid-19 Pandemic on Mental Health of Healthcare Workers in India: A Questionnaire Based Study
}

\author{
Ayaskant Sahoo a, Swikruti Behera ${ }^{b}$ (D) \\ a Department of Anaesthesiology and Critical Care, NRI institute of Medical Sciences, Visakhapatnam, Andhra Pradesh, India. \\ ${ }^{\mathrm{b}}$ Department of Physiology, NRI institute of Medical Sciences, Visakhapatnam, Andhra Pradesh, India.
}

\begin{abstract}
Introduction : Healthcare workers across the globe are working tirelessly to keep the severity under control. The long working hours wearing PPE, the self-quarantine periods, staying away from family, and various other factors does influence the mental wellbeing of an individual. In a country like India mental health is still a poorly recognised issue even among healthcare professionals. Objective : To assess the stress, anxiety and depression among healthcare professionals at the time of Coronavirus pandemic and estimating the same in Anaesthesiology Cohort.

Material \& Methods : The study was conducted using a self-reporting questionnaire. The questionnaire was made using Google forms and the link for participation was sent using various digital mediums e.g., email, WhatsApp, Facebook. The questionnaire was sent to a total of 886 doctors and there was a total of 256 responses were received. The questionnaire was submitted anonymously and no personal data was collected. The respondents were allowed to submit only once to prevent duplicity of response. We used the DASS 21 scale as the assessment tool. Data was collected using google forms and the collected data was transferred to a Microsoft Excel sheet for analysis.

Result : Our study on 256 doctors $40.75 \%$ doctors were found to be suffering from Depression, 38.29\% from anxiety \& $32.4 \%$ from stress in the current pandemic situation. Anaesthesiologists were found to have $30.29 \%$ depression; Anxiety was found among $42.56 \%$ and stress was found among $37.24 \%$.

Conclusion : Stressors, like gruelling shifts, risk of infections, non-availability of protective kits, health risk to family and friends etc, are many and respite seems to be far. We need to address and acknowledge the mental health of healthcare workers and people working in critical care into consideration and find solutions to the underlying causes so that the current and future of the healthcare can be saved from mental health crisis.
\end{abstract}

KEYWORDS : Depression, Anxiety, Stress, Doctors, Anaesthesiologists. Covid-19.

Correspondence: Dr Swikruti Behera, Associate Professor, Physiology Department, NRI IMS, Visakhapatnam, AP, India. Pin -531162. Email : drswikruti@gmail.com

Copyright (C) 2020 Sahoo A \& Behera S.This is an open access article distributed under the Creative Commons Attribution 4.0 International, which permits unrestricted use, distribution, and reproduction in any medium, provided the original work is properly cited.

\section{INTRODUCTION}

Fear and uncertainty of infection, worry of carrying infection to the loved ones, dwindling or inadequate supply of protective kit, everchanging recommendations and guidelines, unusually long and difficult working hours etc are some of the hardships the current healthcare workers worldwide are dealing with. Every job description comes with its share of risks and compromises, but if suddenly the risk increases manifold or becomes inevitable as well as much more dangerous, then it is bound to take a toll on their mental health along with their physical health in the long term. There have been few pandemics in the past and scale of the current COVID 19 pandemics is having a huge impact on the economy as well as healthcare systems across the globe. The most recent pandemic that occurred in India was the Swine Flu pandemic of 2009. But the total number of cases across India over the years due to the H1N1 is 
miniscule compared to the COVID 19. Healthcare workers across the globe are working tirelessly to keep the severity under control. The long working hours wearing PPE, the self-quarantine period of 14 days, staying away from family, and various other factors does influence the mental wellbeing of an individual. In a country like India mental health is still a poorly recognised issue even among healthcare professionals. There has been a case of suspected suicide by a post graduate student posted in COVID 19 hospital and the doctor was suffering from depression. It is of utmost importance that regular assessment of the mental status of healthcare professionals is made for optimal performance of these professionals in these trying times. Apart from mental health still being a taboo in our society, its expanse in unprecedented situation like a pandemic is very crucial. Literature in Indian society is very sparse. Aim of the study : To assess the stress, anxiety and depression among healthcare professionals at the time of Coronavirus pandemic and estimating the same in Anaesthesiology Cohort.

\section{METHODS}

The study was conducted in the month of April \& May 2020 using a self-reporting questionnaire. This was a cross-sectional study done on Indian Healthcare workers to study the prevalence of Mental stress among them. To avoid physical contact and maintain social distancing norm, this study was done via online platform. The questionnaire, which included demographic profiles (age, gender, branch of specialization, type of duties, marital status) and Depression, Anxiety \& Stress scale (DASS21) was made using Google forms and the link for participation was sent using various digital mediums e.g., email, WhatsApp, Facebook. The questionnaire was sent to a total of 886 doctors and there was a total of 256 responses received. The questionnaire was submitted anonymously with no personal data that was collected to avoid bias. Purpose of the study was explained and participants were given the freedom to choose to participate in the study. Consent for study was taken. Respondents were allowed to submit only once to prevent duplicity of response. Doctors having any prior mental or acute physical sickness were excluded from the study. Doctors working in India were sent emails and WhatsApp irrespective of age, gender and place. Data was collected using Google forms and the collected data was transferred to a Microsoft Excel sheet for analysis. Data was analysed using Microsoft Excel.

The questionnaire was sent to 386 contacts by WhatsApp direct message and emailed to 276 doctors. We further asked to share the questionnaire among peers. Total responses we received were 204. Now there can be many factors for the low response we got. Doctors have been receiving a lot of mails inviting to webinars, fill up surveys which dilutes the attention and response. Even the stress related to Covid-19 duties takes a toll on most of the healthcare workers. The link was open for 1 month.

\section{RESULT}

256 doctors have participated in this study. 63 are MBBS doctors, 152 are MD/MS and 41 are super specialists. Out of these 94 were anaesthesiologists and rest of them included 8 paediatricians, 2 radiologists, 6 orthopaedic surgeons, 9 Pulmonary Medicine, 14 general surgery, 20 general medicine, 18 OBG, 18 community medicine, 7 Ophthalmologists, Microbiology 3, Pathologists 6, Physiology 12, Anatomy 2, Neuro Surgery 2, Neurology: 4 and rest were MBBS (63). Out of 256 doctors 139 $(54.29 \%)$ are working in private sector, 52(20.31\%) are in government sector, $43(16.79 \%)$ are Post graduate students and 22 are self-employed (8.5\%). During data collection, 170 doctors were doing non-Covid routine duties (66.4\%), 40 doctors were posted in Active Covid duties $(15.6 \%)$ and 56 doctors were expecting Covid duties ahead $(21.8 \%)$. Table 1 shows the age distribution.

Table 1: Age distribution of participant doctors.

\begin{tabular}{ll}
\hline Age in years & Number of doctors \\
\hline $25-35$ & 148 \\
$35-45$ & 74 \\
$45-55$ & 24 \\
$>55$ & 10 \\
\hline Total & $\mathbf{2 5 6}$ \\
\hline
\end{tabular}

Figure 1 shows sex distribution:

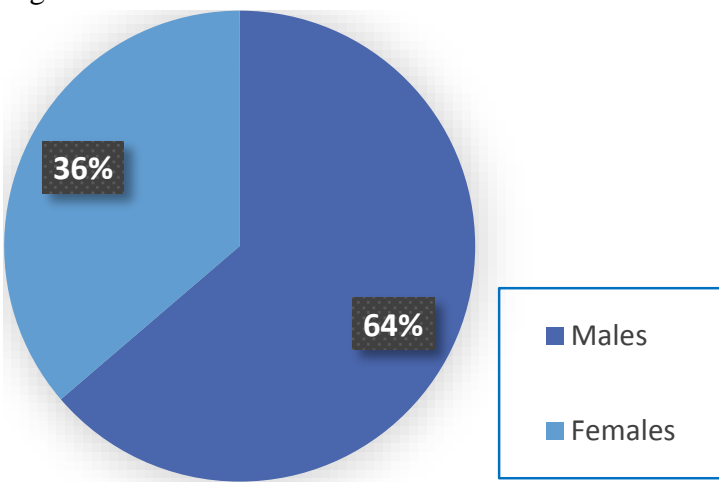

Figure I : Gender distribution among doctors who have participated in the study.

Out of all participants 164 were male and \& 92 were Females

Depression, Anxiety and Stress:

Table $-2 \rightarrow$ Depression: In our study we found 152 respondents to be within Normal range, 48 were having mild depression, 32 were moderately depressed, 8 had severe depression and 16 were suffering from very severe depression.

Table 2 : Distribution of doctors using DASS score for Depression (Normal- 0-9, Mild - 10-12, Moderate - 13-20; Severe- 21-27, Extremely severe - 28-42).

\begin{tabular}{lllll}
\hline Depression $(\mathbf{N = 2 0 4})$ & Males & Females & Total & Percent \\
\hline Normal & 100 & 52 & 152 & $59.37 \%$ \\
Mild & 40 & 8 & 48 & $18.75 \%$ \\
Moderate & 16 & 16 & 32 & $12.5 \%$ \\
Severe & 0 & 8 & 8 & $3.125 \%$ \\
Extremely severe & 4 & 12 & 16 & $6.25 \%$ \\
\hline
\end{tabular}

Table $3 \rightarrow$ Anxiety: 158 responders were within normal range for anxiety, 18 were having mild anxiety, 49 showed moderate anxiety levels, 18 were suffering from 
severe anxiety and 13 were suffering from extremely severe anxiety.

Table 3 : Distribution of doctors using DASS score for Anxiety ( Normal- 0-6, Mild - 7-9, Moderate - 10-14; Severe- 15-19, Extremely severe - 20-42).

\begin{tabular}{lllll}
\hline Anxiety & Males & Females & Total & Percent \\
\hline Normal & 112 & 46 & 158 & $61.71 \%$ \\
Mild & 12 & 6 & 18 & $7.03 \%$ \\
Moderate & 8 & 41 & 49 & $19.14 \%$ \\
Severe & 12 & 6 & 18 & $7.03 \%$ \\
Extremely severe & 5 & 8 & 13 & $5.07 \%$ \\
\hline
\end{tabular}

Table $4 \rightarrow$ Stress: 173 doctors were within the normal levels of stress, 44 were having mild stress, 13 doctors had moderate stress levels and 17 had severe stress, 9/256 of the respondents fell in the extremely stress level category.

Table 4: Distribution of doctors using DASS score for Stress ( Normal- 0-10, Mild - 11-18, Moderate - 19- 26; Severe- 27- 34, Extremely severe - 35-42).

\begin{tabular}{lllll}
\hline Stress & Males & Females & Total & Percent \\
\hline Normal & 120 & 53 & 173 & $67.57 \%$ \\
Mild & 13 & 31 & 44 & $17.18 \%$ \\
Moderate & 2 & 11 & 13 & $5.07 \%$ \\
Severe & 2 & 15 & 17 & $6.64 \%$ \\
Extremely severe & 3 & 6 & 9 & $3.51 \%$ \\
\hline
\end{tabular}

Table $5 \rightarrow$ Depression, Anxiety and Stress (DAS) in anaesthesiologists during Covid 19 (total $\rightarrow$ 84).

Table 5 : DASS score (for Depression, Anxiety and Stress) among Anaesthesiologists.

\begin{tabular}{llcccc}
\hline DAS-21 & Normal & \multicolumn{4}{c}{ Not Normal } \\
\cline { 3 - 5 } & & Mild & Moderate & Severe & Extremely severe \\
\hline Depression & $65(69.74 \%)$ & $16(17.02 \%)$ & $8(8.51 \%)$ & $2(2.12 \%)$ & $3(3.19 \%)$ \\
Anxiety & $54(57.44 \%)$ & $10(10.63 \%)$ & $21(22.34 \%)$ & $4(4.25 \%)$ & $5(5.31 \%)$ \\
Stress & $59(62.76 \%)$ & $11(11.7 \%)$ & $18(19.14 \%)$ & $1(1.06 \%)$ & $5(5.31 \%)$ \\
\hline
\end{tabular}

Anaesthesiologists were found to have $30.29 \%$ depression; Anxiety was found among $42.56 \%$ and stress was found among $37.24 \%$.

\section{DISCUSSION}

Previous researchers had found that healthcare workers live and work under higher stress and psychological distress compared to other professions, even under normal circumstances $(1,2)$. In a pandemic, especially when the threat is enormous and treatment hazy, strain on healthcare personnel increases manifold. Additionally, doctors at the risk of getting infected themselves or infecting their family or loved ones while catering to the affected or patients with unknown status.[3,4] Anaesthesiologists have a highly stressful job profile owing the need for sustained vigilance, unpredictability of work, fear of litigation, competence, grave outcomes, dealing with serious patients in ICU and production pressure.[4,5] Extreme stress among critical care specialists may lead to physical and emotional exhaustion and burnout which can be very deterrent in the long run.

In the current Covid-19 pandemic, our study found $40.75 \%$ doctors were suffering from Depression, 38.29\% were suffering from anxiety \& $32.4 \%$ were suffering from stress. Study done by SS Chatterjee found $34.9 \%$ were depressed and $39.5 \%$ and $32.9 \%$ were having anxiety and stress, respectively which closer to the values that we have found in our studies [6]. Various studies from previous epidemics/pandemics (such as the SARS outbreak from 2003, the MERS epidemic from 2012 or Ebola outbreaks in West Africa) have shown that healthcare professionals have experience several mental health issues $[7,8]$ which might even continue after the outbreak/pandemic is over [9]. Among frontline doctors, $30.29 \%$ anaesthesiologists were found to have depression and $42.56 \%$ were having anxiety and $37.24 \%$ suffered from stress. The anxiety and stress level were found to be higher than the other healthcare workers.
Earlier studies addressing the prevalence of depression among doctors during an epidemic have reported a rate of 26.6\%. [10] Studies done in India showed even higher prevalence of depression and stress under normal circumstances which was found to be $30.1 \%$ depression and $16.7 \%$ doctors had showed suicidal ideation [11].Wang $\mathrm{C}$ et al,. reported moderate to severe anxiety symptoms in $28.8 \%$ healthcare workers and $8.1 \%$ reported moderate to severe stress levels.[12]. We found $30.29 \%$ anaesthesiologists to have depression, $42.56 \%$ having anxiety and $37.24 \%$ having stress. Though the depression level is found to be considerably lower than the other healthcare workers but anxiety and stress are higher by $4.27 \%$ and $4.81 \%$ respectively. Studies have found that under these outbreak condition surgeons, anaesthesiologists are having higher risks than under nonpandemic conditions. [13,14].

Non-standard work hours have been proved to be associated with several chronic outcomes. There is evidence linking shift work to breast cancer and long work hours to stroke. [15] Current health crisis has increased the risks of uncertainty even more, which may lead to graver consequences in future.

We have used DASS-21 questionnaire as our tool which is considered to be a valid tool for assessment of psychological factors such as depression, anxiety and stress. [16,17]

LIMITATIONS: this study was conducted by online platforms hence the response rate was less. A larger study population with equal representation from all specialities is needed to have a more comprehensive idea about the mental health during Covid-19. The contributing factors needs to be assessed to go to the bottom of the causes behind such implications.

CONCLUSION - In our study on 256 doctors we found $40.75 \%$ doctors were suffering from Depression, $38.29 \%$ were suffering from anxiety \& $32.4 \%$ from stress in the 
current pandemic situation. Anaesthesiologists were found to have $30.29 \%$ depression; Anxiety was found among $42.56 \%$ and stress was found among $37.24 \%$.

SUMMARY- As our study reveals, more awareness and prompt screening should be there among doctor community and further long-term planning and risk assessment should be there. Adverse mental health condition will not only affect their service delivery and patient service but it might affect their family and society

\section{AUTHORS' CONTRIBUTIONS}

The participation of each author corresponds to the criteria of authorship and contributorship emphasized in the Recommendations for the Conduct, Reporting, Editing, and Publication of Scholarly work in Medical Journals of the International Committee of Medical Journal Editors. Indeed, all the authors have actively participated in the redaction, the revision of the manuscript and provided approval for this final revised version.

\section{REFERENCES}

[1] Caplan RP. Stress, anxiety, and depression in hospital consultants, general practitioners, and senior health service managers. BMJ 1994; 309(6964): 1261-3. DOI: $10.1136 / \mathrm{bmj} .309 .6964 .1261$

[2] Coomber S, Todd C, Park G, Baxter P, Firth-Cozens J, Shore S. Stress in UK intensive care unit doctors. Br J Anaesth 2002; 89(6):873-81. DOI: 10.1093/bja/aef273

[3] Chen MI, Lee VJ, Barr I, Lin C, Goh R, Lee C, et al. Risk factors for pandemic (H1N1) 2009 virus seroconversion among hospital staff, Singapore. Emerg Infect Dis 2010; 16(10): 1554-61. DOI: 10.3201/eid1610.100516

[4] Shiao JS, Koh D, Lo LH, Lim MK, Guo YL. Factors predicting nurses' consideration of leaving their job during the SARS outbreak. Nurs Ethics 2007; 14(1): 517. DOI: $\underline{10.1177 / 0969733007071350}$

[5] Coomber S, Todd C, Park G, Baxter P, Firth-Cozens J, Shore S. Stress in UK intensive care unit doctors. Br J Anaesth. 2002;89(6):873-81. DOI: 10.1093/bja/aef273

[6] Chatterjee SS, Bhattacharyya R, Bhattacharyya S, Gupta $\mathrm{S}$, Das S, Banerjee BB. Attitude, practice, behavior, and mental health impact of COVID-19 on doctors. Indian Journal of Psychiatry. 2020 May 1; 62(3):257-265. DOI: $10.4103 /$ psychiatry.IndianJPsychiatry $333 \quad 20$

[7] Styra R, Hawryluck L, Robinson S, Kasapinovic S, Fones $\mathrm{C}$, Gold WL. Impact on health care workers employed in high-risk areas during the Toronto SARS outbreak. J Psychosom Res 2008; 64: 177-83. DOI: $10.1016 / j . j p s y c h o r e s .2007 .07 .015$

[8] Sim K, Chong PN, Chan YH, Soon WS. Severe acute respiratory syndrome-related psychiatric and posttraumatic morbidities and coping responses in medical staff within a primary health care setting in Singapore. J Clin Psychiatry 2004; 65(8): 1120-7. DOI: $\underline{10.4088 / j c p . v 65 n 0815}$

[9] Su TP, Lien TC, Yang CY, Su YL, Wang JH, Tsai SL, et al. Prevalence of psychiatric morbidity and psychological adaptation of the nurses in a structured SARS caring unit during outbreak: a prospective and periodic assessment study in Taiwan. J Psychiatr Res 2007;41(1-2):119-30. DOI: $\underline{10.1016 / j . j p s y c h i r e s .2005 .12 .006}$ at large in the long run . Proper measures should be planned and taken into account to reduce the longer duty hours, uncertainty, exhaustion and burnout. As the COVID-19 epidemic continues to sweep and respite nowhere in sight, our findings will be pertinent for the planning and development of inclusive psychological support, identification and treatment for long term benefits in a developing country like India where mental health still remains unaddressed.

\section{STATEMENT OF ETHICS}

The authors have no ethical conflicts to disclose.

\section{DISCLOSURE STATEMENT}

The authors certify that there is no conflict of interest with any financial organization regarding the material discussed in the manuscript.

\section{ACKNOWLEDGEMENT}

None.

[10] Um DH, Kim JS, Lee HW, Lee SH. Psychological effects on medical doctors from Middle East Respiratory Syndrome (MERS) OUTBREAK: Acomparison of whether they worked at MERS occurred hospital or not, and whether they participated in MERS diagnosis and treatment. J Korean Neuropsychiat Assoc 2017: 56(1):2834. DOI: $10.4306 / \mathrm{jknpa} .2017 .56 .1 .28$

[11] Grover S, Sahoo S, Bhalla A, Avasthi A. Psychological problems and burnout among medical professionals of a tertiary care hospital of North India: Across-sectional study. Indian J Psychiatry 2018; 60(2): 175-88. DOI: 10.4103 /psychiatry.IndianJPsychiatry $254 \quad 17$

[12] C. Wang, R. Pan, X. Wan, Y. Tan, L. Xu, C.S. Ho and R.C. Ho. Int. J. Environ. Res. Public Health, 17 (5) (2020), p. E1729. DOI: 10.3390/ijerph17051729

[13] Gupta B, Bajwa SJ, Malhotra N, Mehdiratta L, Kakkar K. Tough times and Miles to go before we sleep- Corona warriors. Indian J Anaesth 2020;64, Suppl S2:120-4. DOI: 10.4103/ija.IJA 56520

[14] Xu J, Xu QH, Wang CM, Wang J. Psychological status of surgical staff during the COVID-19 outbreak. Psychiatry Res. 2020;288:112955. DOI: $\underline{10.1016 / j . p s y c h r e s .2020 .112955}$

[15] Rivera AS, Akanbi M, O'Dwyer LC, McHugh M (2020) Shift work and long work hours and their association with chronic health conditions: A systematic review of systematic reviews with meta-analyses. PLoS ONE 15(4): e0231037. DOI: 10.1371/journal.pone.0231037

[16] Henry JD, Crawford JR. The short-form version of the Depression Anxiety Stress Scales (DASS-21): Construct validity and normative data in a large non-clinical sample. British J of Clinical Psychology. 2005 Jun;44(Pt 2):22739. DOI: $10.1348 / 014466505 X 29657$

[17] Lee J, Lee EH, Moon SH. Systematic review of the measurement properties of the Depression Anxiety Stress Scales-21 by applying updated COSMIN methodology. Qual Life Res. 2019;28(9):2325-2339. DOI: $\underline{10.1007 / \mathrm{s} 11136-019-02177-\mathrm{x}}$ 